\title{
The effects of dog management on Echinococcus spp. prevalence in villages on the eastern Tibetan Plateau, China
}

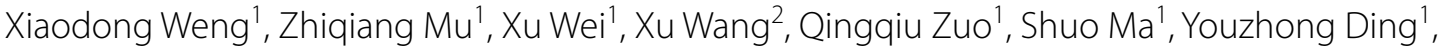 \\ Xiaoming Wang ${ }^{1,3}$, Weiping $W_{u^{2}}$, Philip S. Craig ${ }^{5}$ and Zhenghuan Wang ${ }^{1,4,6^{*}}$
}

\begin{abstract}
Background: The pastoral area of the eastern Tibetan Plateau is highly endemic for human echinococcosis. Domestic dogs are the main definitive host for the transmission of both Echinococcus granulosus (sensu lato) and E. multilocularis to humans. To control the infection risks, a national-level canine echinococcosis prevention and control programme has been implemented since 2015 in Shiqu County, Ganze Tibetan Autonomous Prefecture, Sichuan, China. The objective of this study was to evaluate its effect on Echinococcus spp. prevalence in dogs.
\end{abstract}

Methods: We surveyed 69 households with 84 owned dogs, for dog fecal samples and dog keeping information in the villages of Rizha and Eduoma. A total of 105 dog fecal samples (75 from owned dogs and 30 unknown dog fecal samples) were collected between 2015-2017 to determine Echinococcus spp. prevalence using copro-PCR. Eight variables based on household surveys were included into a logistic regression model for significant risk factors to canine echinococcosis prevalence in dogs.

Results: Between 2015-2017, the overall Echinococcus spp. copro-DNA prevalence decreased significantly in dogs from $51.2 \%$ (2015) to 20.0\% (2017) in Rizha, and insignificantly from 11.5\% (2016) to 4.3\% (2017) in Eduoma. Echinococcus multilocularis was the most prevalent species continually copro-DNA detected during the entire study period, while E. granulosus was rare and not detected in 2017. Echinococcus shiquicus copro-DNA prevalence (a probable non-zoonotic wildlife species) was as high in dogs as that of E. multilocularis, although only detected in 2015 in Rizha. Unleashed dog feces were mainly collected in Rizha in 2015. Although 93.2\% of owned dogs were leashed, and the monthly praziquantel dosing rate reached $97 \%$, E. multilocularis infection could still be detected in $11.1 \%$ of owned dogs in 2017. Monthly deworming, leashing dogs $24 \mathrm{~h}$ per day, and the avoidance of dogs feeding on livestock viscera were significant measures to prevent canine echinococcosis infection in owned dogs.

Conclusions: Carrying out a canine echinococcosis prevention and control programme can significantly decrease Echinococcus spp. prevalence. The potential contact between leashed dogs and wild small mammals is still a risk for re-infection of owned dogs with E. multilocularis. This study shows that the long-term application of regular dog treatment with praziquantel in the vast and remote echinococcosis endemic areas of the eastern Tibetan Plateau can reduce transmission in dogs but remains a challenging intervention.

Keywords: Tibetan Plateau, Shiqu County, Dog management, Feces, Copro-PCR, Prevalence, Echinococcus multilocularis, E. granulosus, E. shiquicus

\footnotetext{
*Correspondence: zhwang@bio.ecnu.edu.cn

1 School of Life Sciences, East China Normal University, Shanghai, China

Full list of author information is available at the end of the article
}

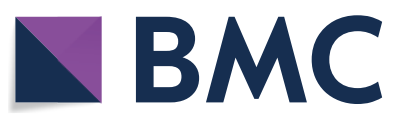

(c) The Author(s) 2020. This article is licensed under a Creative Commons Attribution 4.0 International License, which permits use, sharing, adaptation, distribution and reproduction in any medium or format, as long as you give appropriate credit to the original author(s) and the source, provide a link to the Creative Commons licence, and indicate if changes were made. The images or other third party material in this article are included in the article's Creative Commons licence, unless indicated otherwise in a credit line to the material. If material is not included in the article's Creative Commons licence and your intended use is not permitted by statutory regulation or exceeds the permitted use, you will need to obtain permission directly from the copyright holder. To view a copy of this licence, visit http://creativeco mmons.org/licenses/by/4.0/. The Creative Commons Public Domain Dedication waiver (http://creativecommons.org/publicdomain/ zero/1.0/) applies to the data made available in this article, unless otherwise stated in a credit line to the data. 


\section{Background}

Echinococcosis is a potentially lethal and globally distributed zoonosis, caused by tapeworms from the genus Echinococcus [1]. Two forms of echinococcosis, cystic echinococcosis (CE) caused by infection with the metacestode of E. granulosus (sensu lato) and alveolar echinococcosis (AE) caused by infection with the metacestode of E. multilocularis, were found to be endemic in the pasture areas of western China threatening more than 50 million people [2]. AE is the most severe form of echinococcosis, with a mortality rate reaching $94 \%$ within 10 years without treatment [3]. About $91 \%$ of new cases of human AE reported worldwide occur in China $[4,5]$. Echinococcosis has been listed as a critical endemic disease in China, and patients have been given free treatment from the Chinese national medical system since 2007 [6, 7].

Shiqu County, in Ganze Tibetan Autonomous Prefecture, Sichuan Province, China, is located in the pasture areas of the eastern Tibetan Plateau, has been reported to have the highest international prevalence rate of human echinococcosis, and is one of the most serious endemic regions of the world $[8,9]$. Three Echinococcus species, E. granulosus (s.l.), E. multilocularis and E. shiquicus, coexist in this area. While E. granulosus is mainly transmitted between canids and livestock, $E$. multilocularis and E. shiquicus are mainly transmitted between canids and small mammals [10]. The dog is the only confirmed definitive host of both $E$. multilocularis and E. granulosus in Shiqu County [11, 12]. However, Boufana et al. [13] suspected that dogs may be also viable definitive hosts of $E$. shiquicus because a copro-DNA prevalence of $30 \%$ (6/20) was detected in fecal samples of owned dogs in Shiqu County, although unlike the other two Echinococcus species, E. shiquicus has not been reported currently as infecting humans. As a typical pastoral livestock husbandry county, pastoralism requirements and local Tibetan cultural traditions result in large numbers of owned and stray dogs to be kept in Shiqu County [8]. Because of their close relationships to local people, dogs are considered as the main risk to humans becoming infected with echinococcosis by ingesting Echinococcus eggs voided in dog feces $[9,11]$. Therefore, methods to control the dog population size and decrease Echinococcus prevalence are critical, but a great challenge over many years for the control and prevention of echinococcosis in pastoral Tibetan communities [6,7].

To provide better living conditions, the Chinese central government has started a settlement construction programme for pastoral Tibetan communities from 2004, causing a large expansion in the areas of original villages and towns. In addition, with better education opportunities and medical support, increased settlement of pastoral Tibetan families resulted in an increase in both owned and unowned (stray) dog populations, potentially increasing the risks of transmitting echinococcosis to humans. Therefore, the Chinese central government started a new pilot echinococcosis prevention and control project in Shiqu County in November 2015 [14]. As a crucial part of the project, dog management regulations included restricting the number of owned dogs to no more than two individuals per household, restricting and leashing owned dogs when staying in human settlements, controlling and decreasing the number of unowned dogs through fertility control, fostering, or humane euthanasia, and most importantly deworming registered dogs monthly with praziquantel and burying or burning voided fecal matter.

To evaluate the effects of the dog management regulations, we tested Echinococcus spp. prevalence in dog populations from two villages in Shiqu County from 2015 to 2017. Dog feces were collected, dietary fecal remains were checked, and the copro-PCR method was used to analyze the differences in Echinococcus spp. prevalence in dogs in the two villages and between different years. To evaluate the correlation between the implementation of the control project and Echinococcus spp. prevalence in dogs, questionnaire surveys were carried out, and their results were further compared with fecal sample analytic data. It is hoped that this study can help the evaluation of the effectiveness of dog management and intervention programme in Shiqu and benefit the long-term prevention and echinococcosis control in other pastoral areas of western China.

\section{Methods}

\section{Study area}

Studies were carried out in two villages, Eduoma $\left(33^{\circ} 08^{\prime} \mathrm{N}, 97^{\circ} 47^{\prime} \mathrm{E}\right)$ and Rizha $\left(33^{\circ} 07^{\prime} \mathrm{N}, 97^{\circ} 36^{\prime} \mathrm{E}\right)$ in Serxu Township (the former Eduoma Township, renamed in 2012), Shiqu County, which are located in the eastern Tibetan Plateau, Sichuan Province with an elevation between 4200-4700 m above sea level (Fig. 1). While Eduoma is the elementary education and primary health care center of Serxu Township with 160 houses, Rizha is a remote and smaller village with only 56 houses. All the houses in the two villages were newly built between 2014-2015 for nomadic Tibetan people supported by the central governmental settlement construction programme started in 2004. A local Tibetan family may occupy several houses in the village, due to a large number of family members. Rizha was surveyed in July and August 2015 and 2017, and Eduoma in July and August 2016 and 2017. Traditionally, summer is an important season for pastoralism in Shiqu County, when livestock 
herds need to graze on high elevation summer pasture areas distant from villages during late May to late September. Because many families have transitioned from nomadic to sedentary lifestyles, a cooperative pasturing relationship has been developed. Each year, only a small number of families or people in the village go to the summer pasture to keep livestock herds on behalf of the whole village and some of the owned dogs in the village are taken to summer pastures for shepherding, while families remaining in the village take care of the houses for owners working in summer pastures. Because of the more sedentary lifestyle, dogs are no longer considered absolutely necessary and as a result owned dog numbers in villages have decreased in recent years.

\section{Questionnaires}

In each village, all households were visited. For each family with dogs, a questionnaire concerning information about dog keeping and echinococcosis prevention was given to adult family members. Dog keeping questions included the number of dogs owned, age and sex of each dog. More detailed information about echinococcosis prevention included three questions:

(i) Were dogs restrained from roaming during the past 12 months? Under the dog management regulations, all owned dogs should be leashed $24 \mathrm{~h}$ per day when staying in human settlements. Three kinds of dog keeping methods to restrain the dog roaming behavior in the village area: leashed (always tired up), night free (unleashed dogs at night but tired up in daytime), unleashed (always set free).

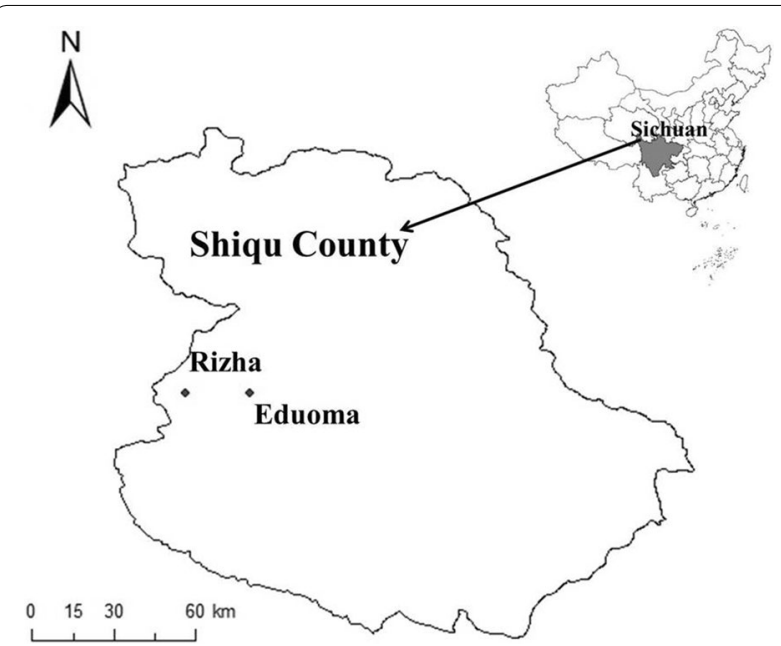

Fig. 1 The geographical location of the study area, Shiqu County, in Sichuan, China (ii) How frequently were dogs dewormed during the past 12 months? According to the regulation, each dog should be dosed by taking one pill containing $0.1 \mathrm{~g}$ praziquantel on the 10th day of each month after its distribution by local government staff who provide the anthelminthic to dog owners for free. Owners however may report to dose their dog (s) monthly, or irregularly (spanning from two to six months per dose), or never (did not dose during the past year).

(iii) What kind of food were owned dogs given during the past one year? Most dog owners would provide dogs with family meal leftovers of mainly roasted barley called Zamba, however, some owners would feed their dogs with livestock viscera when available.

\section{Dog fecal sample collection}

When giving the questionnaire, dog fecal samples were collected from each household. Owned dogs were usually tied up separately, so one dog fecal sample for each owned dog could be collected around its normal tethering place/kennel. If the family owned several dogs and leash places were too near to distinguish feces origin, only one fecal sample was collected. During household visits, the rest of the village was checked to collect unleashed dog (owned or stray dogs) feces and to record numbers of unleashed dogs. All fecal samples were stored separately in screw $50 \mathrm{ml}$ capped tubes with $95 \%$ ethanol. To kill any infective eggs of Echinococcus species, all fecal samples were stored at $-80{ }^{\circ} \mathrm{C}$ for at least one week before further processing [15].

\section{Fecal sample pre-treatment and copro-PCR}

Fecal pre-treatment was carried out according to the method proposed by Jiang et al. [16]. Two to three grams of each dog fecal sample were suspended and stirred in $45 \mathrm{ml}$ of deionized $\mathrm{H}_{2} \mathrm{O}\left(\mathrm{dH}_{2} \mathrm{O}\right)$, incubated at $80{ }^{\circ} \mathrm{C}$ for $10 \mathrm{~min}$, poured into a cell culture dish lined with doublelayer medical sterilize gauze, and squeezed. The residue in the gauze was stored at $4{ }^{\circ} \mathrm{C}$ for dietary analysis. The squeezed suspension in the dish was placed in a $50 \mathrm{ml}$ tube and centrifuged at $3600 \times g$ for $30 \mathrm{~min}$. The supernatant was removed, and the sediment emulsified in $600 \mu \mathrm{l}$ InhibitEx buffer (QIAamp Fast DNA stool mini kit; Qiagen, Hilden, Germany) and incubated at $70{ }^{\circ} \mathrm{C}$ for $10 \mathrm{~min}$. The emulsified liquid was then transferred to a Precellys tube (Peqlab Biotechnology, Erlangen, Germany) and homogenized using an equal amount of Precellys ceramic beads with a diameter of $0.5 \mathrm{~mm}$ (Peqlab Biotechnology) in a Bertin Precellys 24 homogenizer (Bertin Technologies, Aix en Provence, France), at $5500 \times \mathrm{rpm}$ for $15 \mathrm{~s}$. 
This was repeated twice to achieve mechanical disruption of Echinococcus spp. eggs. The supernatant was collected for DNA extraction according to the instruction steps of the QIAamp Fast DNA stool mini kit.

Specific nad1 primers [17] were used to test the coproDNA for Echinococcus species. All PCRs were performed in $25 \mu \mathrm{l}$ volumes with $2 \mu \mathrm{l}$ template DNA, $0.5 \mu \mathrm{l}$ of the primers $(10 \mu \mathrm{mol} / \mathrm{l}), 0.5 \mu \mathrm{l}$ of bovine serum albumin (BSA; TaKaRa, Dalian, China), and $12.5 \mu \mathrm{l}$ Premix Taq (Ex Taq Version 2.0 plus dye; TaKaRa), made up to a final volume of $25 \mu \mathrm{l}$ with $\mathrm{dH}_{2} \mathrm{O}$. The parameters of the PCRs for the three $\operatorname{nad} 1$ specific primer pairs were: $94{ }^{\circ} \mathrm{C}$ for $5 \mathrm{~min}$, followed by 35 cycles of $94^{\circ} \mathrm{C}$ for $30 \mathrm{~s}, 45 \mathrm{~s}$ at the annealing temperature of each primer pair (Table 1), $72{ }^{\circ} \mathrm{C}$ for $90 \mathrm{~s}$, and a final extension step at $72{ }^{\circ} \mathrm{C}$ for 10 min. All PCRs were completed on a DNA thermal cycler (Applied Biosystems Veriti thermal cycler; Life Technologies, Carlsbad, CA USA). Negative controls $\left(\mathrm{dH}_{2} \mathrm{O}\right)$ were included in each PCR run.

PCR products were subjected to agarose gel electrophoresis and stained with ethidium bromide (EB). Positive results indicated that the target gene fragments were amplified. Positive amplicons were excised carefully from the gel and purified with the TIAN gel Midi Purification Kit (Tiangen, Beijing, China). Cloning and sequencing of the purified products were conducted by Sangon Biotech Technology Co. Ltd. (Shanghai, China). Sequences were compared with the sequences on GenBank (http://www. ncbi.nlm.nih.gov/BLAST). Sequences with $\geq 99 \%$ identity were considered to represent specific Echinococcus species.

\section{Fecal sample food remnant analysis}

Remains of each molecular analyzed dog fecal sample were checked for dietary items. The purpose of the food remnant analysis was to double check the questionnaire results and evaluate the possibility of owned dogs preying on intermediate hosts of Echinococcus spp., especially small mammal hosts of E. multilocularis. Checks were made for human food, especially roasted barley, and also the bones and teeth of small mammals such as pikas or voles. Before the analysis, the remains of each molecularly analyzed fecal sample were decontaminated by autoclaving in a wet atmosphere at $180^{\circ} \mathrm{C}$ for $30 \mathrm{~min}$ and washed with water above a sieve (500 $\mu \mathrm{m}$ mesh size) to isolate the undigested food remnants.

\section{Statistics}

We used the Chi-square test to compare the difference in the deworming frequencies and Echinococcus spp. copro-prevalence in dog populations between villages in different years based on data from the copro-DNA analysis and questionnaire. Although the sampling and questionnaire studies started in different years in the two villages, they were both resampled in 2017, two years after the announcement of the pilot echinococcosis control programme in 2015 [14]. The overall deworming rate and Echinococcus spp. copro-prevalence in the two villages in 2017 were used to compare with data collected in earlier years to evaluate the effectiveness of the control programme. It is important to note that since each village was sampled twice in different years, it is not certain whether the questionnaire and fecal samples collected from the same household were actually from the same family and the same dogs between years, due to the cooperative pasturing relationship mentioned earlier; therefore, data from different years for each household were not compared. All statistics were conducted using R 3.5.3 [18].

To evaluate the effect of the dog management and control programme on Echinococcus spp. prevalence in owned dog populations, logistic regression models were built. Echinococcus infection status of each owned dog according to copro-PCR results was the dependent variable by setting "not infected" and "infected" as the binary results. Eight variables based on the location and time of sampling and answers of the questions in the questionnaire were used as independent variables, including feeding habitats (human food and livestock viscera); sex of dogs (male and female); deworming frequency

Table 1 General information of copro-PCRs used in the study [13]

\begin{tabular}{|c|c|c|c|c|c|}
\hline Primer & Species & Target gene & Sequence & $\begin{array}{l}\text { Amplicon length } \\
\text { (bp) }\end{array}$ & $\begin{array}{l}\text { Annealing } \\
\text { temperature } \\
\left({ }^{\circ} \mathrm{C}\right)\end{array}$ \\
\hline \multirow[t]{2}{*}{ E.m } & E. multilocularis & EmF19/3 & TAGTTGTTGATGAAGCTTGTTG & 207 & 53 \\
\hline & & EmR6/1 & ATCAACCATGAAAACACATATACAAC & & \\
\hline \multirow[t]{2}{*}{ E.s } & E. shiquicus & EsF50 & TTATTCTCAGTCTCGTAAGGGTCCG & 442 & 60 \\
\hline & & EsR73 & CAATAACCAACTACATCAATAATT & & \\
\hline \multirow[t]{2}{*}{ E.g } & E. granulosus & Eg1F81 & GTTTTTGGCTGCCGCCAGAAC & 226 & 62 \\
\hline & & Eg1R83 & AATTAATGGAAATAATAACAAACTTAATCAACAAT & & \\
\hline
\end{tabular}


(monthly, irregular and never); village (Rizha and Eduoma); year of survey (2015, 2016 and 2017); number of dogs (owned and kept in each household); dog roaming behavior (leashed, night-free and unleashed) and the age of the dog. Considering the independence requirement of each dog sampled, to the household with multiple dogs, information from only one randomly chosen dog was imported into the model.

The logistic regression model significance level was set to $P<0.05$. The coefficient of determination of the final model was expressed by the Nagelkerke $R^{2}$ [19]. The logistic regression model analysis was conducted using SPSS 23.0 (IBM, 2015).

\section{Results}

During the entire research period, 69 households covering 318 people (owners of 84 dogs) were questioned and 105 dog fecal samples were collected from 75 from owned dogs and 30 from unleashed dogs (Table 2). Seven unleashed dogs were observed in Rizha Village in 2015 and one unleashed dog was recorded in Eduoma Village in 2016. No unleashed dogs were observed in either village in 2017.

\section{Questionnaire}

\section{Dog ownership, sex and age distribution}

No household was recorded keeping more than two dogs in the two villages during the entire study period (Table 3), with a mean number of $1.2 \pm 0.42( \pm \mathrm{SD})$ dogs kept in each of the 69 visited households. There was no significant difference in the number of dogs kept per household detected between the two villages and between years (Rizha 2015 vs 2017, $\chi^{2}=0.007, d f=1$, $P=0.933$; Eduoma 2016 vs 2017, $\chi^{2}=0.017, d f=1, P$ $=0.896)$. Most dogs owned by pastoralists were male (83.1\%) (Table 3). Among the 84 recorded dogs, information of sex and age was matched in 67 individuals and ages were mainly 4 years-old or younger (67.2\%)
(Fig. 2), ranging from less than one year to more than 10 years-old.

\section{Dog roaming behavior}

Most of the recorded dogs in the two villages (93.2\%) were kept leashed and the proportion of dogs kept leashed did not differ between villages and years (Table 3). No all-day unleashed owned dogs were recorded during the entire research period. Night-free dogs were reported from one Rizha household (7.1\%) in 2015 and four Eduoma households (16\%) in 2016 (Table 3). In 2017, 100\% of the households in Rizha and Eduoma that responded to the questionnaire, kept their dogs leashed $24 \mathrm{~h}$ per day. No significant $X^{2}$ analysis results of the difference in the dog roaming behavior (i.e. leashed/night free) were detected between years and villages, respectively: (i) Rizha 2015 vs 2017, $x^{2}=0.019, d f=1, P=0.891$; (ii) Eduoma 2016 vs 2017, $\chi^{2}=0.162, d f=1, P=0.687$; (iii) Rizha $v s$ Eduoma in 2017, $\chi^{2}=0.022, d f=1, P=0.882$.

\section{Deworming frequency and feeding behavior}

The dog monthly deworming rate was $93 \%$ in Rizha in 2017, according to the responses from visited households (Table 3). However, in 2015 no dogs in Rizha were reported to be dewormed monthly during the past year (Table 3). In addition the deworming frequency (i.e. monthly/(irregular + never)) was significantly different among years for Rizha (2015 vs 2017, $\chi^{2}=5.850, d f=$ $1, P=0.016)$. In Eduoma, the monthly deworming rates were always high and there was no significant difference between the rates in 2016 and $2017\left(\chi^{2}=0.035, d f=1, P\right.$ $=0.853)$. There was no significant difference in the rate of dogs monthly deworming between Rizha and Eduoma in $2017\left(\chi^{2}=0.021, d f=1, P=0.886\right)$

All households in Rizha in 2015 and 2017 responded that they fed dogs with family left-over food, especially roasted barley. However, in Eduoma in 2016 three households owning five dogs, and in 2017 three households owning four dogs, responded that they also fed their dogs livestock viscera when available (Table 3 ).

Table 2 Summary of questionnaires and fecal sample collection in Rizha and Eduoma villages, Shiqu County, Sichuan, China, between 2015-2017

\begin{tabular}{|c|c|c|c|c|c|c|}
\hline \multirow[t]{2}{*}{ Year } & \multirow[t]{2}{*}{ Village } & \multirow[t]{2}{*}{ No. of questionnaires } & \multicolumn{2}{|c|}{ No. of dogs recorded } & \multicolumn{2}{|c|}{ No. of fecal samples collected } \\
\hline & & & Owned & Unleashed & Owned & Unleashed \\
\hline 2015 & Rizha & 11 & 14 & 7 & 14 & 27 \\
\hline 2016 & Eduoma & 27 & 31 & 1 & 25 & 1 \\
\hline 2017 & Rizha & 12 & 16 & 0 & 14 & 1 \\
\hline 2017 & Eduoma & 19 & 23 & 0 & 22 & 1 \\
\hline Total & & 69 & 84 & 8 & 75 & 30 \\
\hline
\end{tabular}


Table 3 Summary of 69 questionnaires from Rizha and Eduoma villages, Shiqu County, Sichuan, China, between 2015-2017

\begin{tabular}{|c|c|c|c|c|c|}
\hline \multirow[t]{2}{*}{ Subjects in the questionnaire } & \multirow[t]{2}{*}{ Sampling village } & \multirow[t]{2}{*}{ Dog status } & \multicolumn{3}{|c|}{ No. of owned dogs (No. of households) } \\
\hline & & & 2015 & 2016 & 2017 \\
\hline \multirow[t]{2}{*}{ Number of dogs recorded $(n=84)$} & Rizha & & $14(11)$ & - & $16(12)$ \\
\hline & Eduoma & & - & $31(27)$ & $23(19)$ \\
\hline \multirow[t]{4}{*}{$\operatorname{Sex}(n=71)$} & Rizha & Male & $11(10)$ & & $13(11)$ \\
\hline & & Female & $1(1)$ & & $1(1)$ \\
\hline & Eduoma & Male & & $20(20)$ & $15(14)$ \\
\hline & & Female & & $7(7)$ & $3(3)$ \\
\hline \multirow[t]{6}{*}{ Roaming behavior $(n=73)$} & Rizha & Leashed & $13(10)$ & - & $14(12)$ \\
\hline & & Night free & $1(1)$ & - & 0 \\
\hline & & Unleashed & 0 & - & 0 \\
\hline & Eduoma & Leashed & - & $21(21)$ & $20(18)$ \\
\hline & & Night free & - & $4(4)$ & 0 \\
\hline & & Unleashed & - & 0 & 0 \\
\hline \multirow[t]{6}{*}{ Deworming frequency $(n=67)$} & Rizha & Monthly & - & - & $13(11)$ \\
\hline & & Irregular & $5(4)$ & - & $1(1)$ \\
\hline & & Never & $6(5)$ & - & 0 \\
\hline & Eduoma & Monthly & - & $23(23)$ & $17(15)$ \\
\hline & & Irregular & - & $2(2)$ & 0 \\
\hline & & Never & - & 0 & 0 \\
\hline \multirow[t]{4}{*}{ Feeding habits $(n=84)$} & Rizha & Human food & $14(11)$ & - & $16(12)$ \\
\hline & & Viscera & 0 & - & 0 \\
\hline & Eduoma & Human food & - & $31(27)$ & $23(19)$ \\
\hline & & Viscera & - & $5(3)$ & $4(3)$ \\
\hline
\end{tabular}

Abbreviation: $\mathrm{n}$, number of owned dogs recorded

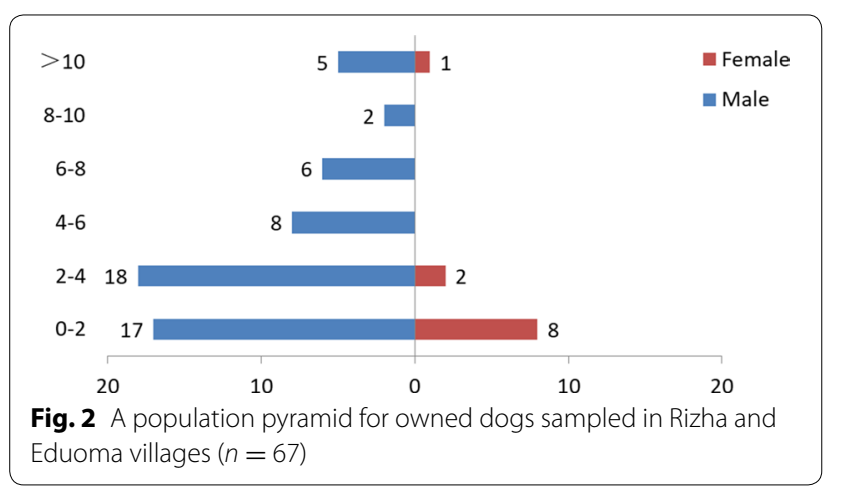

Copro-DNA Echinococcus spp. prevalence in dogs

All 105 fecal samples were tested by Echinococcus coproPCR analysis. In general, the overall Echinococcus coproprevalence in dogs in Rizha decreased significantly from $51.2 \%$ in 2015 to $20.0 \%$ in $2017\left(x^{2}=6.850, d f=\right.$ $1, P=0.009$ ), while the prevalence in Eduoma was low at $11.5 \%$ in $2016,4.3 \%$ in 2017 , and not significantly different between the two sampling years $\left(\chi^{2}=0.842, d f=\right.$ $1, P=0.359)$ (Table 4). Although the overall Echinococcus prevalence in the first sampling year in Rizha (2015) was significantly higher than that in Eduoma (2016) $\left(\chi^{2}=\right.$ $4.485, d f=1, P=0.034)$, the difference in prevalence was not significant in $2017\left(\chi^{2}=0.700, d f=1, P=0.404\right)$.

DNA sequences of E. multilocularis, E. shiquicus and E. granulosus were all detected in dog fecal samples by copro-PCR analysis. Echinococcus multilocularis and E. shiquicus were the main Echinococcus species detected in Rizha dog fecal samples in 2015 (Table 4), and the prevalence of these two species were not significantly different $\left(\chi^{2}=0.502, d f=1, P=0.479\right)$. Meanwhile, the prevalence of E. multilocularis and E. shiquicus were both significantly higher than that of E. granulosus ( $E$. multilocularis vs E. granulosus, $\chi^{2}=14.168, d f=1, P<0.001$; E. shiquicus vs E. granulosus, $X^{2}=10.464, P<0.001$ ). However, E. multilocularis was the only Echinococcus species constantly detected in owned dogs in both villages during the entire study period, although the prevalence declined (Table 4). Echinococcus shiquicus was only detected in dogs in Rizha in 2015 and E. granulosus was only detected from two unleashed and one owned dog fecal samples in the two villages during the first sampling years, while both E. granulosus and E. shiquicus not detected in 2017 (Table 4). Feces of unleashed dogs were mainly collected in Rizha in 2015 (Table 2) and the 
Table 4 Statistics of the Echinococcus copro-DNA prevalence in owned and unleashed dogs in Rizha and Eduoma villages, Shiqu County, Sichuan, China, between 2015-2017

\begin{tabular}{|c|c|c|c|c|c|c|}
\hline Village & Year & Dog status & E. multilocularis & E. shiquicus & E. granulosus & Echinococcus spp. \\
\hline \multirow[t]{3}{*}{ Rizha } & \multirow[t]{3}{*}{2015} & Owned & $50.0(26.8-73.2)(7 / 14)$ & $28.6(9.6-58.0)(4 / 14)^{a}$ & $0(0 / 14)$ & $50.0(26.8-73.2)(7 / 14)$ \\
\hline & & Unleashed & $48.1(29.2-67.6)(13 / 27)$ & $40.7(23.0-61.0)(11 / 27)^{b}$ & $3.7(0.1-20.9)(1 / 27)^{c}$ & $51.9(32.4-70.8)(14 / 27)$ \\
\hline & & Sub-total & $48.8(33.2-64.6)(20 / 41)$ & $36.6(22.6-53.1)(15 / 41)$ & $2.4(1.3-14.4)(1 / 41)$ & $51.2(35.4-66.8)(21 / 41)$ \\
\hline \multirow[t]{3}{*}{ Eduoma } & \multirow[t]{3}{*}{2016} & Owned & $4.00(0.2-22.3)(1 / 25)$ & $0(0 / 25)$ & $4.0(0.2-22.3)(1 / 25)$ & $8.0(1.4-27.5)(2 / 25)$ \\
\hline & & Unleashed & $0(0 / 1)$ & $0(0 / 1)$ & $-(1 / 1)$ & $-(1 / 1)$ \\
\hline & & Sub-total & $3.8(20.2-21.6)(1 / 26)$ & $0(0 / 26)$ & $7.7(1.3-26.6)(2 / 26)$ & $11.5(3.0-31.3)(3 / 26)$ \\
\hline \multirow[t]{3}{*}{ Rizha } & \multirow[t]{3}{*}{2017} & Owned & $21.4(5.7-51.2)(3 / 14)$ & $0(0 / 14)$ & $0(0 / 14)$ & $21.4(5.7-51.2)(3 / 14)$ \\
\hline & & Unleashed & $0(0 / 1)$ & $0(0 / 1)$ & $0(0 / 1)$ & $0(0 / 1)$ \\
\hline & & Sub-total & $20(5.3-48.6)(3 / 15)$ & $0(0 / 15)$ & $0(0 / 15)$ & $20(5.3-48.6)(3 / 15)$ \\
\hline \multirow[t]{3}{*}{ Eduoma } & \multirow[t]{3}{*}{2017} & Owned & $4.6(0.1-9.0)(1 / 22)$ & $0(0 / 22)$ & $0(0 / 22)$ & $4.6(0.1-9.0)(1 / 22)$ \\
\hline & & Unleashed & $0(0 / 1)$ & $0(0 / 1)$ & $0(0 / 1)$ & $0(0 / 1)$ \\
\hline & & Sub-total & $4.3(0.2-24.0)(1 / 23)$ & $0(0 / 23)$ & $0(0 / 23)$ & $4.3(0.2-24.0)(1 / 23)$ \\
\hline \multirow[t]{2}{*}{ Rizha and Eduoma } & \multirow[t]{2}{*}{2017} & Owned total & $11.1(3.6-27.0)(4 / 36)$ & $0(0 / 36)$ & $0(0 / 36)$ & $11.1(3.6-27.0)(4 / 36)$ \\
\hline & & Total & $10.5(3.4-25.7)(4 / 38)$ & $0(0 / 38)$ & $0(0 / 38)$ & $10.5(3.4-25.7)(4 / 38)$ \\
\hline
\end{tabular}

a Four owned dogs were detected mixed infection of E. multilocularis and E. shiquicus

b Ten unleashed dog fecal samples were detected with mixed infection of E. multilocularis and E. shiquicus

c One unleashed dog fecal sample was detected with mixed infection of E. granulosus, E. multilocularis and E. shiquicus

Note: Data are presented as follows: prevalence $(95 \% \mathrm{Cl})$ in $\%$ (number of positive fecal samples/total number of fecal samples examined)

copro-prevalence of the three Echinococcus species could be as high as or even higher than those of owned dogs in the same year (Table 4), although differences were not significant $\left(\chi^{2}=0.013, d f=1, P=0.910\right)$.

\section{Fecal food remnant analysis}

Most of the dog feces contained remains of roasted barley (97.1\%). Small mammal teeth and bones were only found in three dog fecal samples, including one unleashed dog fecal sample from Rizha in 2015, one owned dog fecal sample from Rizha in 2016 and one owned dog fecal sample from Eduoma in 2017.

\section{Significant variables related to the prevalence of Echinococcus in owned dogs}

Among the 75 fecal samples from owned dogs, data from 59 qualified to enter the logistic regression model. The final model revealed that three significant variables influencing the Echinococcus infection of owned dogs in villages were the deworming frequency, sex of dogs and their feeding habits (Nagelkerke $R^{2}=0.492$, Table 5). Monthly deworming seemed to be vital to reduce the prevalence of canine echinococcosis, because irregular or no deworming could resulted in the infection odds ratio (OR) to increase from 23.3 to 52.5 times (Table 5). Echinococcus spp. prevalence showed a significant sex bias in dogs with male dogs having infection risks more than 1000 times higher than female dogs (Table 5). Feeding dogs with livestock viscera was the third statistically significant risk causing Echinococcus spp. prevalence to increase $(\mathrm{OR}=23.3, P=0.021)$. Feeding dogs with livestock viscera is judged as a main risk of E. granulosus infection. However, since only two fecal samples with $E$. multilocularis infection and no E. granulosus infection were detected from the six fecal samples from households reporting feeding dogs on viscera, no further analysis of the feeding habits variable using logistic regression models was carried out.

\section{Discussion}

The huge pastoral area of the eastern Tibetan Plateau, as typically represented by Shiqu County (Sichuan Province), has been recognized as one of the most serious echinococcosis endemic regions in the world $[8,20]$. Thus, Shiqu has been listed by the Chinese government as a pilot area of the national programme for prevention and control of echinococcosis [21]. The increasing prevention awareness of echinococcosis in Tibetan communities has resulted in a better implementation of dog population management, regular deworming and changes to better dog feeding. As an important part of the pilot project, the dog management work has significantly reduced the prevalence of canine echinococcosis since its implementation in 2015 (Table 5).

According to the NDRC in 2016 [7], the population size of stray dogs must be controlled and decreased and the canine echinococcosis prevalence in dog populations should be less than $5 \%$ in endemic areas by the end of 2020. The dog management regulations were strictly implemented in Rizha right after the beginning of the 
Table 5 Binary logistic regression analysis of significant variables associated with Echinococcus spp. infections in owned dogs

\begin{tabular}{llllll}
\hline Variable & State & \multicolumn{2}{l}{ Infection test } & P-value & Odds ratio \\
\cline { 3 - 4 } & & Infected & Uninfected & & \\
\hline Deworming & Monthly & 3 & 45 & 0.010 & 1 \\
frequency & Never & 2 & 3 & 0.021 & 23.3 \\
& Irregular & 3 & 3 & 0.004 & 52.5 \\
Sex & Female & 0 & 8 & - & 1 \\
& Male & 8 & 43 & 0.001 & $>1000$ \\
\hline
\end{tabular}

Shiqu county-wide implementation of the echinococcosis prevention and control programme in November 2015 [14]. The questionnaire and copro-PCR results showed very high Echinococcus spp. prevalence (51.2\%) in dogs in Rizha in the summer of 2015, which was significantly decreased (20\%) by 2017, two years after the implementation of the dog management regulations (Table 4). By contrast, a trial of the dog management regulations has been carried out in Eduoma Village since 2014, earlier than the county-wide implementation, thus the low Echinococcus spp. prevalence in Eduoma recorded in 2016 and 2017 (Table 4) was not unexpected. The overall Echinococcus spp. prevalence in owned dogs in Eduoma was less than 5\% in 2017 (Table 4), which met the standard baseline defined by NDRC [7] and an obvious decreasing trend in Echinococcus spp. prevalence in the dog population was confirmed by our current surveillance data.

The importance of dog population control for echinococcosis has been studied in detail by some reports [20, 22]. Although the regulations of the dog management programme have been implemented in Shiqu County for many years $[23,24]$, it needs time to cover all the remote areas of the county. For example, numbers of owned dogs per household of the two target villages were less than two on average which was below the number permitted by the dog management regulations, and furthermore dog ownership was not different between villages or between sampling years. However, stray dog populations were different (Table 2). In Eduoma, the dog population has been strictly controlled since 2014, and presence of unleashed dogs was unusual during the entire sampling period of this study (Table 2). In the more remote Rizha, unleashed dogs were still common place in 2015, and it was where the majority of the unleashed dog feces and unleashed dogs in this study were recorded (Table 2). Numbers of unleashed dog associated feces significantly decreased in 2017 and in that years unleashed dogs were not observed (Table 2). Although dog feces might also have come from unleashed owned dogs, judging by the high rate of awareness of echinococcosis control and prevention in the community (Table 3 ) and the reduction in numbers of unleashed dogs and ground feces collected, this probably reflected improved control of the unowned stray dog population. In general, the present data indicated that the dog management measures did significantly reduce Echinococcus spp. prevalence in local populations of dogs in some villages in Shiqu County and should be sustained for effective echinococcosis control in pastoral Tibetan communities.

All of the three Echinococcus spp. reported in China were detected infecting dogs in our study (Table 4). Echinococcus granulosus and E. multilocularis are the two confirmed zoonotic species. The overall prevalence of E. multilocularis was significantly higher than that of $E$. granulosus in dogs in our study (Table 4) and this was similar to previous observations $[11,25]$. The prevalence of E. shiquicus copro-DNA could be as high as E. multilocularis in dog feces (Table 4), which further supported the possibility of dogs as a viable definitive host species of E. shiquicus, as suggested by Boufana et al. [13]. Although no transmission to humans has been reported, E. shiquicus shares a sylvatic transmission cycle with $E$. multilocularis between canids and small mammal species [13, 26, 27]. Echinococcus multilocularis was the main and the only Echinococcus species continuously detected in dogs, especially in owned dogs in the two visited villages in all sampling years (Table 4). Compared with preventing owned dogs from becoming infected with E. granulosus by ingesting livestock viscera, it would seem more difficult to stop the trophic connection between owned dogs and small mammals to prevent infection with $E$. multilocularis. Factors influencing the Echinococcus spp. prevalence in owned dogs are important for dog targeted control measures in the pastoral areas of the Tibetan Plateau.

Free roaming has been considered a significant risk for infections of owned dogs with E. multilocularis and E. shiquicus, but not with E. granulosus in Shiqu County because of their high chances of contact with and preying upon wild intermediate host small mammals [11, 25]. Unleashed dogs can be active within and around Tibetan villages, as shown by Vaniscotte et al. [12] who reported that a released owned dog could move up to 1500 m away from the village with an average activity area of $77 \pm$ 59.4 ha. Such an active spatial behavior pattern enables a free-roaming dog to visit areas where wild small mammal intermediate host species may be distributed. The average worm lifespan of E. granulosus and E. multilocularis is probably ten and five months respectively [1], so theoretically preventing contact with intermediate hosts, deworming an infected dog and restraining roaming behavior are considered as effective methods to control Echinococcus spp. prevalence in owned dogs [7]. Because almost all households from the two Tibetan villages 
claimed to leash their dogs 24 hours per day according to questionnaire results, there were not enough negative samples to result in the dog roaming behavior being assessed as an insignificant variable by the logistic regression analysis. The questionnaire results suggested however that, as an important part of health education, leashing dogs had been generally accepted and followed by the two communities.

However, the fact that copro-DNA of E. multilocularis was continually detected in owned dogs indicated that owned dogs still have chances to come into contact with small mammal host species. Small mammal bones were detected in feces of a few owned dogs and a minority of households released dogs at night (Table 3). Even if people leashed dogs as instructed, leashed dogs may also be able to prey on peri-domestic small mammals. At least six widespread small mammal species, mainly voles and pikas have been identified in Shiqu County as intermediate hosts of E. multilocularis [20] and the prevalence in voles species was significantly higher than that in pikas $[23,28,29] . \mathrm{Mu}[30]$ confirmed that the population density of small mammals especially vole species can be high less than $500 \mathrm{~m}$ away from Rizha Village. In fact, evidence of small mammal presence could be as near as 32 $\mathrm{m}$ away from households in villages of Shiqu County [12]. Therefore, infected small mammals may have the opportunity to access the villages, which may provide leashed dogs opportunities to prey upon them. Moreover, when herding on the summer pasture, owned dogs are usually unleashed all the time and these dogs could be infected by preying on small mammals before they come back to the village. Therefore, although restraining dogs is considered a fundamental measure to decrease Echinococcus spp. prevalence in owned dogs, proactive measures such as regular dosing with praziquantel are still needed.

Regular supervised dog praziquantel dosing has been considered to be the pivotal measure for echinococcosis control and prevention in the pastoral areas of the Tibetan Plateau [6], beginning in northwest Sichuan Province in 2006 [31]. The logistic regression model revealed that monthly dosing was significantly more powerful than irregular or no dosing to decrease Echinococcus spp. prevalence in owned dogs (Table 5). Protoscoleces of E. multilocularis and E. granulosus (s.s.) usually need four to six weeks to respectively develop into adult tapeworms after infection [1], so monthly dog deworming has been adopted as the most important control measure.

However, the application of monthly dog dosing in remote settled and semi-nomadic Tibetan communities is challenging. In the more remote Rizha Village, none of the owned dogs surveyed were monthly dosed in 2015 and one household stated in 2017 that they had not received any praziquantel for more than half a year. Because of the obvious difficulty in seasonal traffic transport restrictions, communications and the highly mobile semi-nomadic Tibetan lifestyles (despite permanent settlements being provided), administration of monthly dosing in remote communities is still difficult to enforce in all families. Although monthly dosing regulation can be effectively supervised in some settlements as demonstrated by our data in 2016 and 2017, the effectiveness of monthly dog dosing cannot be easily supervised in summer pasture areas where nomadic families scatter on the vast high-altitude grasslands. This emphasizes the extreme importance of supervised monthly dosing of owned dogs when semi-nomadic families gather in permanent settlements in villages from late September to late May.

Long-term supervised dog dosing programmes can be extremely costly and resource-demanding. The several successful applications of regular praziquantel dosing were usually associated with E. granulosus control in more developed agricultural areas [32-34]. In those regions $E$. granulosus is mainly transmitted between large herbivorous livestock and dogs, therefore coupled with livestock slaughter and viscera management, long term dog dosing can result in a significant impact to the transmission cycle [35]. With regards to the more pathogenic E. multilocularis in the co-endemic regions of eastern Tibetan Plateau, more complex wildlife transmission cycles are present involving wild canids such as the Tibetan fox (Vulpes ferrilata) and the red fox ( $V$. vulpes) [16] and small mammals, such as pikas and small rodent species [27]. The large populations and dispersed distribution of small mammals [27, 36, 37], and their potential predation by dogs (even potentially when leashed), suggests that the possibility of $E$. multilocularis spreading from the wildlife reservoir to the human environment always exists. Once a regular dosing programme stops, Echinococcus spp. prevalence in dogs can return to pre-treatment levels in less than ten months [25], so in order to keep up the long-term regular dog dosing programme to cover the vast western pastoral areas of China, He et al. [28] suggested decreasing the dosing frequency from once per month to once per every two or three months as recommended by the WHO [38]. Their recommendation referred to dog re-infection studies of E. granulosus, however not enough empirical data regarding E. multilocularis re-infection in Tibetan dogs are available yet. Our study suggests that interruption of dosing for several months can significantly decrease the power of the praziquantel dosing. Because of its shorter prepatent infection period and more complex transmission cycles, compared with E. granulosus, successful interruption of transmission of $E$. multilocularis with consideration 
of public health and economic feasibility still requires applied research.

A single dose of praziquantel is recommended to be $5 \mathrm{mg} / \mathrm{kg}$ for dogs [1]. At present, the one-dog-one-pill (0.1 g praziquantel) dosage per month neglects individual weight differences among dogs. Tibetans frequently expressed their concerns about the potential negative side effects of the drug during surveys in villages. The possible use of slow release praziquantel [39] may be a better choice for future large-scale implementation though such formulations require further assessment.

Dogs being male and older are two significant factors associated with higher Echinococcus spp. infection [11]. The significant effect of dogs being male was detected by the logistic regression model in this study. Traditionally, male dogs are preferred by Tibetan pastoralists for both better property and livestock protection and easier dog population management in the community. Because of the development of new settlements and the cooperative pasturing in nomadic local communities, people no longer need as many dogs as before. Controlling breeding activities by keeping only male dogs is usually one of the most feasible methods for remote and developing areas [22]. The proportion of male dogs is significantly higher than female dogs in local communities of Shiqu County in the present and previous studies [25, 40]. Compared with female dogs, male dogs are more likely to maintain territories and hunt, increasing the chances of infection. However, male territorial behavior and hunting are only important when dogs are unleashed. Therefore, if dogs were tied up well as reported by the most visited households, the fact that all canine echinococcosis infections were detected in male dogs in this study should be the result of male dogs being the majority (Table 5) but not a significant infection risk. As to the age bias, the infection burden of E. granulosus could be significantly higher in dogs over five years-old, but not significant for $E$. multilocularis infection $[11,20]$. In the present study, the fact that most of sampled dogs were less than five years-old and E. multilocularis was the main Echinococcus species but not E. granulosus (Table 5) might explain the insignificant effect of dog age.

Not feeding dogs with livestock viscera has frequently been recommended as one of the most effective methods to control domestic dogs infecting E. granulosus [41-43]. Since we did not detect E. granulosus infection in the fecal samples from viscera-fed dogs, the importance of dog feeding habits cannot be evaluated directly by the logistic regression model analysis. Nevertheless, the importance of not feeding dogs with livestock viscera is still significant in this study. In fact, most visited households reported being aware of and did not feed dogs with viscera (Table 3), and the prevalence of E. granuluosus decreased dramatically and was not detected in both villages in the last sampling year of the study (Table 4). All of these results suggest that the regulation to stop feeding dogs with livestock viscera has been well proceeded in local Tibetan communities and received expected effect.

\section{Conclusions}

This study confirmed that, as a crucial part of the Chinese echinococcosis prevention and control project, the current dog management programme has significantly decreased the unowned dog population size and the prevalence of canine echinococcosis in dogs in two Tibetan villages of Shiqu County, Sichuan Province. Supervised monthly dosing with praziquantel was the most important method to reduce copro-prevalence of canine echinococcosis in owned dogs. Additionally, leashing dogs all the time in villages and avoidance of dogs feeding on livestock viscera were significant control measures. The sex and age of dogs may not be significant risks in the two villages, but the potential contact between leashed dogs and infected small mammals is worthy of special attention. Although only a small number of dogs were taken to summer pastures from the villages, the infection dynamics of these dogs remains undetermined. This study also confirmed the presence of $E$. shiquicus DNA in dog feces. Although significant reductions in canine echinococcosis prevalence were detected, the long-term application of regular dog dosing in the vast remote endemic areas of west China remains challenging and further data are required on optimal dosing frequency from these coendemic areas.

\section{Abbreviations}

AE: alveolar echinococcosis; CE: cystic echinococcosis; SD: standard deviation; nad1: NADH dehydrogenase subunit 1 gene; NDRC: National Development and Reform Commission; WHO: World Health Organization.

\section{Acknowledgements \\ We thank the colleagues from National Institute of Parasitic Diseases, Chinese Center for Disease Control and Prevention and Sichuan Center of Disease Control, for their help with field research. Colleagues from the Shiqu County Center of Disease Control provided vital logistical support during the field study. Professor Patrick Giraudoux from University of Franche-Comté provided the picture of stray dogs in front of a village for the graphic abstract. We are grateful to the anonymous reviewers for their invaluable comments to improve the original manuscript.}

\section{Authors' contributions}

XW performed field research, molecular analysis, data processing, and was the major writer of the manuscript. ZM performed molecular analysis of fecal samples. XW, XW, YD carried out the field research. QZ and SM performed laboratory analysis of specimens. XMW designed the study. WW and PSC contributed in the research design and drafting the manuscript. ZW was the main investigator of the study, performed study design, data analysis and manuscript drafting. All authors read and approved the final manuscript. 


\section{Funding}

This study was financially supported by National Science Foundation of China (NSFC No. 31071944 and No. 31470488) and Ministry of Science and Technology of China (No. 2015FY1 10200 and No. 2016YFC0503200).

\section{Availability of data and materials}

All data generated or analyzed during this study are included in this published article. The newly generated sequences of Echinococcus shiquicus were submitted to the GenBank database under the accession numbers MT259952MT259957. No new haplotypes of E. multilocularis and E. granulosus were generated in this study.

\section{Ethics approval and consent to participate Not applicable.}

\section{Consent for publication}

Not applicable.

\section{Competing interests}

The authors declare that they have no competing interests.

\section{Author details}

${ }^{1}$ School of Life Sciences, East China Normal University, Shanghai, China. ${ }^{2}$ National Institute of Parasitic Diseases, Chinese Center for Disease Control and Prevention, Shanghai, China. ${ }^{3}$ Shanghai Science and Technology Museum, Shanghai, China. ${ }^{4}$ Joint Translational Science \& Technology Research Institute, East China Normal University, Shanghai, China. ${ }^{5}$ School of Environment and Life Sciences, University of Salford, Greater Manchester, UK. ${ }^{6}$ Shanghai Key Laboratory of Urbanization and Ecological Restoration, East China Normal University, Shanghai, China.

Received: 4 December 2019 Accepted: 13 April 2020

Published online: 21 April 2020

\section{References}

1. Thompson RCA, Mcmanus DP. Aetiology: parasites and life cycles. In: Eckert J, Gemmell MA, Meslin FX, Pawlowski ZS, editors. WHO/OIE manual on echinococcosis in humans and animals: a public health problem of global concern. Geneva: World Health Organization; 2001. p. 1-17.

2. Wang GQ. Epidemiological survey on echinococcosis in China. 1st ed. Shanghai: Shanghai Science and Technology Press; 2016.

3. Pawlowski ZS, Eckert J, Vuitton DA. Echinococcosus in humans: clinical aspects, diagnosis and treatment. In: Eckert J, Gemmell MA, Meslin FX, Pawlowski ZS, editors. WHO/OIE manual on echinococcosis in humans and animals: a public health problem of global concern. Geneva: World Health Organization; 2001. p. 20-72.

4. Torgerson PR, Keller K, Magnotta M, Ragland N. The global burden of alveolar echinococcosis. PLoS Neglect Trop Dis. 2010;4:e722.

5. Torgerson PR, Macpherson CNL. The socioeconomic burden of parasitic zoonoses: global trends. Vet Parasitol. 2011;182:79-95.

6. National Health and Family Planning Commission of the People's Republic of China. Echinococcosis prevention action plan (2010-2015). 2010. http://www.gov.cn/zwgk/2010-12/14/content_1765485.htm. Accessed 24 Dec 2010.

7. National Development and Reform Commission. National plan for echinococcosis and other key parasitic diseases prevention (2016-2020). 2016. http://www.ndrc.gov.cn/fzgggz/fzgh/ghwb/gjjgh/201707/t2017 0720_855025.html. Accessed 24 Oct 2016.

8. Li TY, Qiu J, Yang W, Craig PS, Chen XW, Xiao N, et al. Echinococcosis in Tibetan populations, western Sichuan Province, China. Emerg Infect Dis. 2005;11:1866-73.

9. Li TY, Chen XW, Zhen R, Qiu JM, Qiu DC, Xiao N, et al. Widespread coendemicity of human cystic and alveolar echinococcosis on the eastern Tibetan Plateau, northwest Sichuan/southeast Qinghai, China. Acta Trop. 2010;113:248-56.

10. Wang $Z \mathrm{H}$, Wang $X M$, Liu XQ. Echinococcosis in China, a review of the epidemiology of Echinococcus spp. EcoHealth. 2008;5:115-26.
11. Budke CM, Campos-Ponced M, Wang Q, Torgerson PR. A canine purgation study and risk factor analysis for echinococcosis in a high endemic region of the Tibetan Plateau. Vet Parasitol. 2005;127:43-9.

12. Vaniscotte A, Raoul F, Poulle ML, Roming T, Dinkel A, Takahashi K, et al. Role of dog behavior and environmental fecal contamination in transmission of Echinococcus multilocularis in Tibetan communities. Parasitology. 2011;138:1316-29.

13. Boufana B, Qiu JM, Chen XW, Budke CM, Campos-Ponced M, Craig PS. First report of Echinococcus shiquicus in dogs from eastern QinghaiTibet Plateau region, China. Acta Trop. 2013;127:21-4.

14. The People's Government of Sichuan Province. 2015. http://www.sc.gov. cn/10462/10464/10797/2015/11/11/10358339.shtml. Accessed $11 \mathrm{Nov}$ 2015.

15. Eckert J, Gottstein B, Heath D. Prevention of echinococcosis in humans and safety precautions. In: Eckert J, Gemmell MA, Meslin FX, Pawlowski ZS, editors. WHO/OIE manual on echinococcosis in humans and animals: a public health problem of global concern. Geneva: World Health Organization; 2001. p. 240-9.

16. Jiang W, Liu N, Zhang GT, Renqing PC, Xie F, Li TY, et al. Specific detection of Echinococcus spp. from the Tibetan fox (Vulpes ferrilata) and the red fox (V.vulpes) using copro-DNA PCR analysis. Parasitol Res. 2012;111:1531-9.

17. Boufana B, Umhang G, Qiu JM, Chen XW, Lahmar S, Boué F, et al. Development of three PCR assays for the differentiation between Echinococcus shiquicus, E. granulosus (G1 genotype), and E. multilocularis DNA in the co-endemic region of Qinghai-Tibet Plateau, China. Am J Trop Med Hyg. 2013:88:795-802.

18. R Core Team. R: A language and environment for statistical computing. Vienna: R for Statistical Computing; 2019.

19. Nagelkerke NJD. A note on a general definition of the coefficient of determination. Biometrika. 1991;78:691-2.

20. Craig PS, Giraudoux P, Wang ZH, Wang Q. Echinococcosis transmission on the Tibetan Plateau. Adv Parasit. 2019;104:165-246.

21. Lu ZP, Yuan DB, Yang AG, Guo L, Hou W, Huang CQ, et al. Overview and prospects of the pilot project of animal echinococcosis in Shiqu County, Sichuan Province. China Anim Health. 2017;19:74-5.

22. Kachani M, Heath D. Dog population management for the control of human echinococcosis. Acta Trop. 2014;139:99-108.

23. He W, Shang JY, Chen F, Zhong B, Zhang Q. Regularity of canine echinococcosis in epidemic areas in Sichuan. J Pre Med Inf. 2018;34:136-9.

24. Zou GT. Experience of hydatid disease prevention and control in Ganzi Prefecture, Sichuan Province. China Anim Health. 2017;19:58-62.

25. Moss JE, Chen X, LiTY, Qiu JM, Wang Q, Giraudoux P, et al. Reinfection studies of canine echinococcosis and role of dogs in transmission of Echinococcus multilocularis in Tibetan communities, Sichuan, China. Parasitology. 2013;140:1685-92.

26. Xiao N, Nakao M, Qiu JM, Budke CM, Giraudoux P, Craig PS, et al. Dual infection of animal hosts with different Echinococcus species in the eastern Qinghai-Tibet Plateau region of China. Am J Trop Hyg. 2006;75:292-4.

27. Wang X, Liu JY, Zuo QQ, Mu ZQ, Weng XD, Sun XH, et al. Echinococcus multilocularis and Echinococcus shiquicus in a small mammal community on the eastern Tibetan Plateau: host species composition, molecular prevalence, and epidemiological implications. Parasit Vectors. 2018:11:302.

28. He JG, Qiu JM, Liu FJ, Chen XW, Liu DL, Chen WD, et al. Epidemiological survey on hydatdosis in Tibetan region of western Sichuan II. Infection situation among domestic and wild animals. Chin J Zoono. 2000;16:62-5.

29. Giraudoux P, Pleydell D, Raoul F, Quéré JP, Wang Q, Yang YR, et al. Transmission ecology of Echinococcus multilocularis: what are the ranges of parasite stability among various host communities in China? Parasitol Int. 2006;55:S237-46.

30. Mu ZQ. Comparative study on the community structure, spatial distribution of burrows and infection rate of echinococcosis of rodents and pika in wild and human living environment. MSc Thesis, East China Normal University, Shanghai, China; 2018.

31. WHO. Report of the WHO Informal Working Group on cystic and alveolar echinococcosis surveillance, prevention and control, with the participation of the Food and Agriculture Organization of the United Nations and the World Organization for Animal Health. Geneva: World Health Organization. https://www.who.int/echinococcosis/resources/9789241502924/ en/. 
32. Cabrera PA, Parietti S, Haran G, Benavidez V, Lloyd S, Perrera G, et al. Rates of reinfection with Echinococcus granulosus, Taenia hydatigena, Taenia ovis and other cestodes in a rural dog population in Uruguay. Int J Parasitol. 1996;26:79-83.

33. Jimenez S, Perez A, Gil H, Schantz PM, Ramalle E, Juste RA. Progress in control of cystic echinococcosis in La Rioja, Spain: decline in infection prevalences in human and animal hosts and economic costs and benefits. Acta Trop. 2002;83:213-21.

34. Craig PS, Larrieu E. Control of cystic echinococcosis/hydatidosis: 1863-2002. Adv Parasitol. 2006;61:443-508.

35. Craig PS, Hegglin D, Lightowlers MW, Torgerson P, Wang Q. Echinococcosis: control and prevention. Adv Parasitol. 2017;96:55-158.

36. Wang Q, Raoul F, Budke CM, Craig PS, Xiao YF, Vuitton DA, et al. Grass height and transmission ecology of Echinococcus multilocularis in Tibetan communities, China. Chin Med J (Peking). 2010;123:61-7.

37. Raoul F, Quéré JP, Rieffel D, Bernard N, Takahashi K, Scheifler R, et al. Distribution of small mammals in a pastoral landscape of the Tibetan Plateau (western Sichuan, China) and relationship with grazing practices. Mammalia. 2006;70:214-25.

38. Eckert J, Gemmell MA, Meslin FX, Pawlowski ZS. WHO/OIE manual on echinococcosis in humans and animals: a public health problem of global concern. Geneva: World Health Organization; 2001.

39. Jiang B, Zhou XN, Zhang HB, Yao Y, Huo LL, Liu N. Slow release praziquantel for dogs: presentation of a new formulation for echinococcosis control. Infect Dis Poverty. 2017;6:140.
40. Wang Q, Yu WJ, Zhong B, Shang JY, Huang L, Mastin A, et al. Seasonal pattern of Echinococcus re-infection in owned dogs in Tibetan communities of Sichuan, China and its implications for control. Infect Dis Poverty. 2016;5:60-7.

41. Schantz PM, Wang H, Qiu J, Liu FJ, Saito E, Emshoff A, Ito A, Roberts JM, Delker C. Echinococcosis on the Tibetan Plateau: prevalence and risk factors for cystic and alveolar echinococcosis in Tibetan populations in Qinghai Province, China. Parasitology. 2003;127(Suppl.):S109-20.

42. Wang $Q$, Huang $Y$, Huang $L$, Yu WJ, He W, Zhong B, et al. Review of risk factors for human echinococcosis prevalence on the Qinghai-Tibet Plateau, China: a prospective for control options. Infect Dis Poverty. 2014;3:3.

43. Yuan R, Wu H, Zeng H, Liu P, Xu Q, Gao L, et al. Prevalence of and risk factors for cystic echinococcosis among herding families in five provinces in western China: a cross-sectional study. Oncotarget. 2017;8:91568-76.

\section{Publisher's Note}

Springer Nature remains neutral with regard to jurisdictional claims in published maps and institutional affiliations.
Ready to submit your research? Choose BMC and benefit from:

- fast, convenient online submission

- thorough peer review by experienced researchers in your field

- rapid publication on acceptance

- support for research data, including large and complex data types

- gold Open Access which fosters wider collaboration and increased citations

- maximum visibility for your research: over 100M website views per year

At BMC, research is always in progress.

Learn more biomedcentral.com/submissions 